\title{
Storage of thermal reactor fuels - Implications for the back end of the fuel cycle in the UK
}

\author{
David Hambley ${ }^{*}$ \\ National Nuclear Laboratory, NNL Central Laboratory, B170, Sellafield, Seascale, Cumbria, CA20 1PG, UK
}

Received: 2 November 2015 / Accepted: 18 February 2016

Published online: 15 April 2016

\begin{abstract}
Fuel from UK's Advanced Gas-Cooled Reactors (AGRs) is being reprocessed, however reprocessing will cease in 2018 and the strategy for fuel that has not been reprocessed is for it to be placed into wet storage until it can be consigned to a geological disposal facility in around 2080. Although reprocessing of LWR fuel has been undertaken in the UK, and this option is not precluded for current and future LWRs, all utilities planning to operate LWRs are intending to use At-Reactor storage pending geological disposal. This strategy will result in a substantial change in the management of spent fuel that could affect the back end of the fuel cycle for over a century. This paper presents potential fuel storage scenarios for two options: the current nuclear power replacement strategy, which will see 16 GWe of new capacity installed by 2030 and a median strategy, intended to ensure implementation of the UK's carbon reduction target, involving 48 GWe of nuclear capacity installed by 2040. The potential scale, distribution and timing of fuel storage and disposal operations have been assessed and changes to the current industrial activity are highlighted to indicate potential effects on public acceptance of back end activities.
\end{abstract}

\section{Introduction}

Spent fuel from the UK's first (Magnox) and second (Advanced Gas Reactor, AGR) generation power reactors has been reprocessed since the reactors came into service, in line with the UK government's position that spent fuel represents an asset.

In 2006, the Nuclear Decommissioning Authority (NDA) was formed to manage the decommissioning of the UK's historic civil nuclear legacy sites, particularly the research sites and the first generation power reactors, which were still in government control, and the reprocessing plants at Sellafield.

There are plans to build new nuclear generating capacity in the UK. The initial phase is expected to add around $16 \mathrm{GWe}$ of capacity by 2030. Decarbonisation of energy use in the UK may require additional nuclear generating capacity, for which a mid-term nuclear capacity of $48 \mathrm{GWe}$ has been proposed.

This paper describes the current industry structure and responsibilities for spent fuel management as a background for a more detailed description of the likely scale of spent fuel storage requirements over the coming century. This

\footnotetext{
* email: david.i.hambley@nnl.co.uk
}

will lead to a consideration of options for optimisation of storage-related activities and to an evaluation of the potential impact of these changes on public perception of nuclear power generation in the UK.

\section{Current spent fuel management}

The UK has three groups of power reactor spent fuel, described below, as well as around 300 te of irradiated nonstandard or experimental fuel. The experimental fuels are not considered in detail here, because they are included in the NDA's decommissioning programme [1] and the focus of this paper is on the larger spent fuel inventories from power reactors.

UK government's policy is that spent fuel management is a matter for the commercial judgment of its owners, subject to meeting the necessary regulatory requirements. The owners of current power reactors are: NDA in respect of Magnox and remaining shutdown experimental reactors and EDF in relation to AGRs and the Sizewell B Pressurised Water Reactor (PWR).

All the first generation Magnox power reactors have shutdown, with the last operational station, Wylfa, closing in December 2015. Magnox fuel is metallic, consisting of uranium metal bar tightly enclosed within magnesiumaluminium alloy cladding. Spent Magnox fuel is reprocessed 

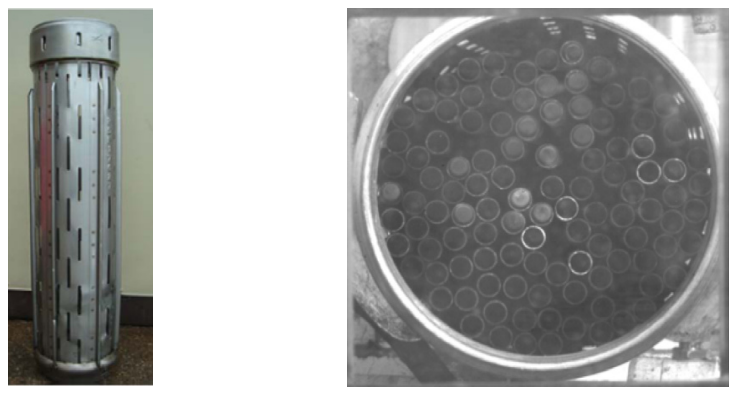

Fig. 1. AGR slotted storage can.

and all remaining fuel from the UK's Magnox reactors will be reprocessed at Sellafield in the Magnox Reprocessing Plant [2].

The liability for decommissioning of the Magnox reactors (and operation of Wylfa until its closure) lies with the NDA who employs a site management company to operate the sites. The NDA has established a Magnox Operating Plan to manage the discharge of fuel from shutdown reactors, transport of fuel to Sellafield, interim storage and reprocessing, so as to minimise risk to spent fuel in storage and ensure maximum utilization of the reprocessing plant.

AGR fuel is discharged from the reactors and held in temporary storage in reactor coolant until the fuel can be separated into individual elements, after which it is stored in station ponds. On-site pond storage continues until the fuel can be shipped to centralised interim storage at Sellafield, typically between 90 and 180 days. Fuel is stored for a further period until it is dismantled and the fuel pins are consolidated for storage (Fig. 1), reducing storage volume by about $1 / 3$.

AGR fuel is stored in caustic dose ponds until required for reprocessing. The fuel is then transported to the reprocessing facility pond, which also holds LWR fuel from international customers.

EDF operates the AGR reactors and has contracts with NDA for reprocessing of fuel. NDA is responsible for the operation of the Sellafield site and reprocessing operations. In 2012, recognising that THORP was approaching the end of its existing reprocessing contracts and certain parts of the infrastructure supporting the reprocessing plant was ageing, NDA completed a review of options for future management of AGR fuel [3]. This review concluded that reprocessing of AGR would cease when existing reprocessing contracts were completed in around 2018 and the remaining AGR fuel and fuel discharged subsequently from AGR reactors would be placed into wet storage using existing storage facilities pending geological disposal. This option did not preclude future reprocessing or a change to alternative storage options and provided storage conditions that would enable monitoring of fuel during storage.

Sizewell B is the only Light Water Reactor (LWR) power station in the UK and is owned by EDF. EDF has contracts that would provide an option to reprocess the fuel at Sellafield but has chosen to store the spent fuel from the reactor on-site, pending disposal. To increase storage capacity at the site, EDF has decided to use dry cask storage, which is currently undergoing licensing approval [4].

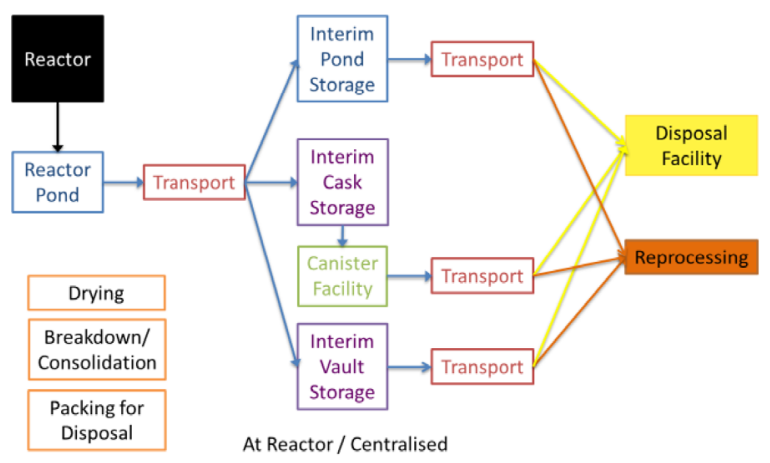

Fig. 2. A spent fuel storage system.

The UK government recognises nuclear power as a low carbon energy source and is considering pathways that could deliver up to $75 \mathrm{GW}$ installed nuclear capacity by $\sim 2050$. The immediate programme is for 16 GWe capacity to be installed by the early 2030s to replace the capacity of the current fleet. The mid-range forecast is consistent with decarbionisation of transport infrastructure and would see installed nuclear capacity of around $48 \mathrm{GWe}$ by 2050 . The option for a future transition to a closed fuel cycle remains open [5].

Unlike earlier power stations, the new generation power stations under development have been justified on the basis of on-site interim storage of spent fuel followed by geological disposal. Alternative spent fuel management options, such as centralised storage or reprocessing, are not precluded, however they would have to be justified prior to implementation.

As with Sizewell B, the owners of the new power stations will be responsible for the management of the spent fuel from discharge until disposal.

The UK has long had a strategy to dispose of intermediate and high levels radioactive wastes in a deep geological disposal facility (GDF) [6]. Since 2010 the inventory of the GDF has been expanded to include spent fuels remaining at the end of reprocessing, future arisings of AGR fuel, spent fuel from Sizewell B and spent fuel from the first tranche of new build reactors (i.e. $16 \mathrm{GWe}$ capacity) $[7,8]$.

In this evaluation of spent fuel storage options, it is the above industry structure and policy framework that is considered.

\section{Input data and assumptions}

The inventory of spent fuel that could be produced by new build reactors has previously been presented [9] based on use of the Orion fuel cycle modelling code, which was developed to model potential advanced fuel cycles. The model did not provide any detailed modelling of options involving storage and transition to disposal. A conceptual model of storage operations between fuel discharge from reactor and emplacement in a GDF is shown in Figure 2.

This study provided a preliminary assessment of such options using simplified assumptions about the generation of spent fuel. It focusses on the accumulation of spent fuel 
Table 1. Operating assumptions for existing reactors.

\begin{tabular}{llll}
\hline Reactor & $\begin{array}{l}\text { Power } \\
{[\text { GWe }]}\end{array}$ & $\begin{array}{l}\text { Spent fuel } \\
{[\text { teU/year }]}\end{array}$ & End date \\
\hline Hunterston B & 0.96 & 26 & 2031 \\
Hinkley point B & 0.95 & 26 & 2031 \\
Dungeness B & 1.05 & 29 & 2031 \\
Heysham A & 1.26 & 34 & 2027 \\
Hartlepool & 1.18 & 32 & 2027 \\
Heysham B & 1.23 & 33 & 2031 \\
Torness & 1.19 & 32 & 2031 \\
Sizewell & 1.20 & 29 & 2055 \\
\hline
\end{tabular}

that results from the opposing effects of discharges from reactor and emplacements in a GDF. For this study, the location of spent fuel storage facilities (e.g. reactor ponds or centralised storage) and storage options (e.g. dry storage casks, dry vaults or ponds) are not resolved. Estimates of the number of fuel shipments to disposal facilities have been made as these are useful in conceptualising potential mass flows and because they represent a real potential impact on host communities.

\subsection{Existing reactor fleet}

Discharges of AGR fuel are based on current nominal power output of AGR reactors and declared decommissioning plans of the operator [10-12]. The operating assumptions presented in Table 1 represent those likely to result in the worst case (largest) spent fuel quantities.

At the end of reprocessing it is estimated that around 1,500 teU of AGR fuel will remain in interim storage [13]. Although there are many differences in reactor design, as indicated by nominal power generation, an average core inventory of $246 \mathrm{teU}$ [14] has been assumed, giving a total fuel inventory at the end of generation of just under 6,000 teU.

Sizewell B has accumulated around 600 teU in pond storage [15]. It is assumed that Sizewell life extension will be in line with the generators declared anticipation, 20 years [10]. With a core inventory of $89 \mathrm{teU}$ [16], the end of life spent fuel inventory will be around 1,615 teU.

\subsection{New build reactors}

For new build reactors exact plans for delivering $16 \mathrm{GWe}$ of capacity have not been declared in detail, however publically available information has been used in conjunction with government planning assumptions [5], of 16 GWe capacity by $\sim 2030$, to yield the modelling assumptions in Table 2.

For a higher generation target, additional capacity is assumed to come on line at an approximately constant rate between 2030 and 2050. It is assumed that the proportion of different reactor types is as shown in Table 2 .
Table 2. Operating assumptions for new build $16 \mathrm{GWe}$ reactors.

\begin{tabular}{lll}
\hline Reactor & Start date & Ref. \\
\hline EPR-1 (Hinkley C) & 2023 & {$[17]$} \\
EPR-2 & 2025 & {$[$ est.] } \\
AP1000-1 & 2024 & {$[19]$} \\
ABWR-1 \& 2 & 2025 & {$[18]$} \\
AP1000-1 & 2025 & {$[19]$} \\
AP1000-3 & 2026 & {$[19]$} \\
EPR-3 \& 4 & 2028 & {$[$ est.] } \\
ABWR-3 \& 4 & 2029 & [est.] \\
\hline
\end{tabular}

est.: the data was estimated, in the absence of declared operational dates, so that total installed capacity met government planning assumptions [5].

Core inventory data and rates of spent fuel generation have been obtained from data in the Generic Design Approval submissions (Tab. 3). For all new build reactors, it is assumed that the nominal fuel burn-up is $55 \mathrm{GWd} / \mathrm{teU}$ and that the reactors will operate for the design life of 60 years. Assessments have also been made for higher burnup (65 GWd/teU) and for extended operation (80 years).

\subsection{Disposal}

In order to model spent fuel management strategies and options it is vitally important to understand the parameters controlling transition of fuel from storage to either reprocessing or disposal. For the purposes of this study, only disposal options have been examined, since the Orion already provides sophisticated modelling of closed fuel cycles.

Radioactive Waste Management, a subsidiary of the NDA, has carried out a number of assessments of the disposability of UK spent fuels. Where the GDF geology has a significant impact on disposability parameters, results for the most restrictive geology have been used. For spent fuel, the reference case is the KBS-3V concept in a granitic geology. Important parameters are listed below:

- LWR fuel assemblies per canister: 4 [26];

- AGR fuel canisters per canister: 16 [27];

- minimum cooling time for new build reference fuel

(65 GWD/teU burn-up): 140 years [26];

- initial spent fuel receipts in GDF: 2075;

- maximum throughput of GDF: 650 teU/year [26].

Changes in fuel burn-up affect the minimum cooling time at which fuel can be accepted into the GDF. For this assessment, this has been approximated by finding the cooling time at which the heat output of higher burn-up fuel equals that of the reference fuel at the reference cooling time. This implicitly assumes that both fuels follow similar time-dependence of heat output and that the heat output at the time of the peak repository temperature is adequately estimated by this approximation. For MOX fuel, this approximation is unlikely to hold, hence MOX fuel is not considered here. 
Table 3. Data for spent fuel assessment for new build reactors.

\begin{tabular}{llll}
\hline Reactor & $\begin{array}{l}\text { Power } \\
{[\text { GWe] }}\end{array}$ & $\begin{array}{l}\text { Core Inv. } \\
{[\text { teU] }}\end{array}$ & $\begin{array}{l}\text { Spent Fuel } \\
{[\text { teU } / \text { year] }}\end{array}$ \\
\hline EPR- & 1.65 & $127[20]$ & $28[21]$ \\
ABWR & 1.35 & $154[22,23]$ & $26[22]$ \\
AP1000 & 1.12 & $85[24,25]$ & $22[24]$ \\
\hline
\end{tabular}

Specific heat outputs have been calculated for a reference PWR fuel obtained using NNL's FISPIN inventory code. Differences between the three LWR reactor types are considered to be sufficiently small that this approximation will not significantly affect the overall pattern of spent fuel inventories.

In order to provide an initial estimate of required transport operations, the number of spent fuel shipments has been estimated using the maximum flask capacity that can be accommodated on current UK transport infrastructure, which is $12 \mathrm{LWR}$ fuel assemblies [26]. For AGR fuel, it is assumed for current purposes that transport packages similar to current designs would be used, with an inventory of 12 consolidated fuel cans. If fuel were to be loaded into disposal containers at a site other than the GDF, new transport flasks would need to be designed and maximum inventories may change, however the base line assumptions are considered adequate for current assessments, since the controlling factor is GDA throughput.

\section{Inventory profiles for reference disposal parameters}

Spent fuel inventories have been calculated in order to indicate the scale (total quantity) and duration of spent fuel storage requirements for the most likely range of medium term deployment of nuclear power in the UK. For this work, medium-term deployment is taken to be capacity installed by around 2050 and likely range of deployments is taken to be between $16 \mathrm{GWe}$ and $48 \mathrm{GWe}$ of new build capacity.

Existing reactors are assumed to operate to best estimates of maximum operating lives with no significant changes in reactor performance characteristics. As indicated earlier, new build reactors are assumed to irradiate fuel to either $55 \mathrm{GWd} /$ teU (reference) or $65 \mathrm{GWd} /$ teU (high burn-up). Where a higher fuel burn-up is assumed, spent fuel discharges are assumed to be reduced in proportion to the increase in discharge burn-up. Reactors are assumed to operate for either 60 or 80 years at nominal power.

\subsection{Generation profiles}

The generation and spent fuel discharge profiles for two cases are presented:

- a lower reference case: the current reactor plus a 16 GWe new build programme operating for 60 years at nominal burn-up;

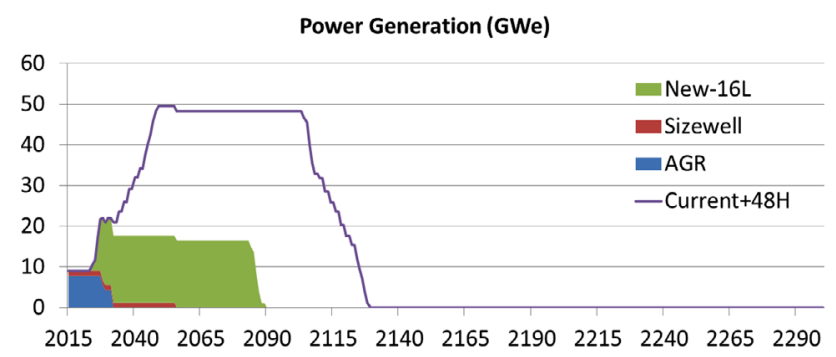

Fig. 3. Generation profiles for lower and higher reference cases.

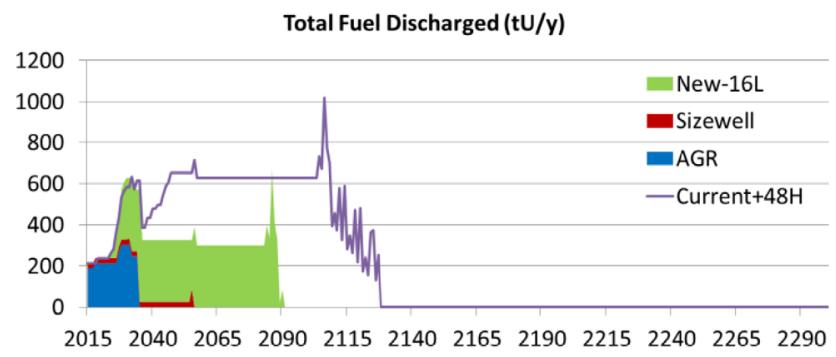

Fig. 4. Spent fuel discharges for lower and higher reference cases.

- a higher reference case: the current reactor fleet plus 48 GWe of new build capacity, reactor life extension of 20 years and a higher average burn-up;

- profiles are shown in Figure 3 for generation and Figure 4 for spent fuel discharges. The peaks in spent fuel discharges represent final core discharges.

It is immediately apparent from Figure 4 that the spent fuel discharges from this larger fleet are at times greater than the reference acceptance capacity for the disposal site (650 teU/y) and would be continuously greater if the larger fleet was operated at the nominal burn-up rather than the increased one, as this would generate an additional $115 \mathrm{teU} /$ year. The current GDF spent fuel inventory includes only fuel from a 16 GWe new build programme [9], therefore additional capacity would have to be provided for a larger programme. Any further GDF development at the same or a different site should clearly have a greater capacity to receive fuel than the current reference design.

\subsection{Storage profile low reference case}

The profile of fuel in storage for this case is shown in Figure 5.

The storage requirement for AGR fuel is provided by existing assets, which are expected to operate until all the AGR fuel is discharged. The requirements for fuel storage at Sizewell B is assumed to be met using the current strategy; reactor storage pond with additional dry cask storage capacity as required to maintain generation. At the end of generation, it is likely that the spent fuel pool inventory would be moved to a long-term storage system to allow reactor decommissioning.

For fuel from new build reactors, long-term storage will be required from around 2035, rising to around 20,000 teU in 2090 and remaining at this level for at least 40 years 


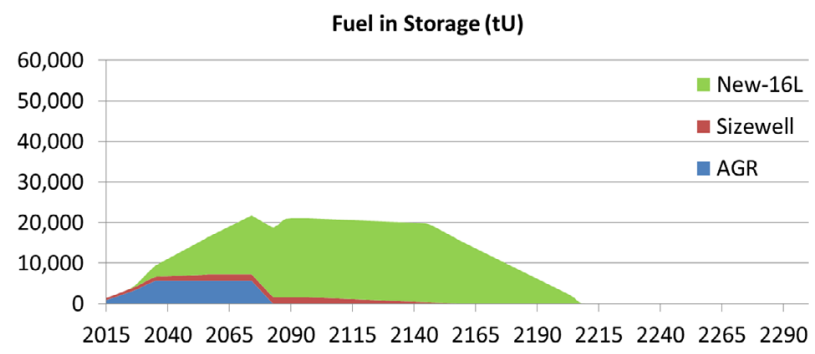

Fig. 5. Spent fuel storage requirements for low reference case.

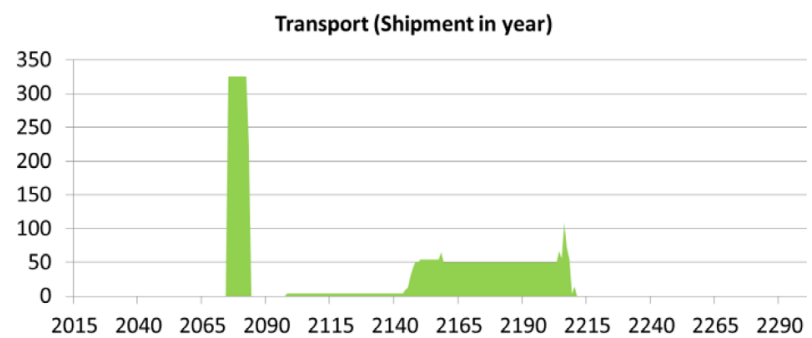

Fig. 6. Fuel transport requirements for low reference case.

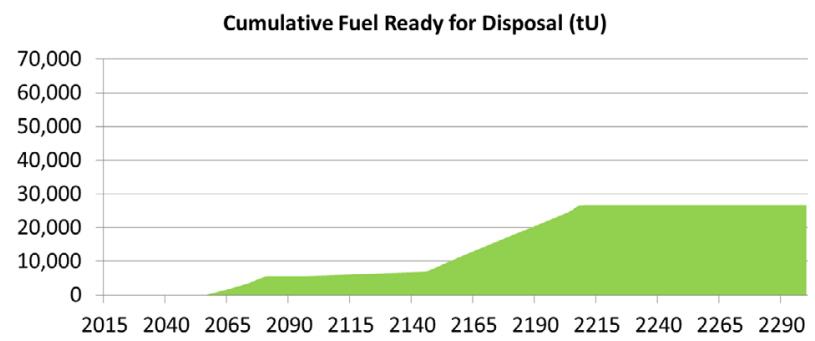

Fig. 7. Spent fuel availability for disposal for low reference case.

before shipments to disposal can begin. Whilst cask storage systems allow for incremental increases in storage capacity, for this scenario even large scale pond storage capacity could be added incrementally at 10-15 years intervals to match storage requirements, providing economies of scale (by implication from Ref. [21]) and greater flexibility in fuel management.

Figure 6 shows the pattern of transport flask shipments. The initial 'spike' is caused by the build-up of AGR fuel available for disposal prior to the anticipated date at which spent fuel can be placed in the GDF (Fig. 7). In practice this would be smoothed out to remove very high throughput requirements at the storage facility. Overall, the system would have to be able to deliver around 150 cuboid flask shipments per year between the storage and disposal sites.

It is also worth noting that the UK has had a history of routine spent fuel shipments from power stations to centralised storage facilities, which will cease a few years after the AGR stations cease generation if fuel storage at reactor sites is adopted at new build sites. Fuel shipments to a GDF would then have to be restarted after a period of around 30-40 years with little or no spent fuel shipment activity. This would require significant mobilisation activities to develop and approve transport packages suitable for AGR fuel, increase regulatory capacity for

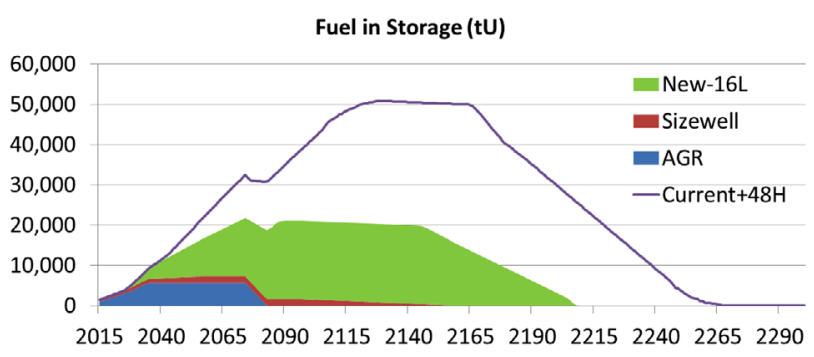

Fig. 8. Spent fuel storage requirements for high reference case.

higher workloads and to train and qualify a workforce with no experience of routine transports. Introduction of a potential hazardous activity in the public domain may be a cause of public concern, which could cause delays, or worse, to shipment programmes.

Post-AGR shipments there would be a small interval of around 15 years before routine shipments of LWR fuel from Sizewell B to the disposal facility. These would continue at a very low rate (around 4/year) for around 35 years before increasing to around 50/year as the fuel from new build reactors became ready for disposal. Although it is likely that different flasks may be required for LWR fuel, to AGR, the short gap between end of AGR and start of LWR shipments would make it more likely that a cadre of experienced staff would be maintained and restart activities would be less onerous.

\subsection{Storage profile high reference case with 20 -year reactor life extension}

The profile of fuel in storage for this case is shown in Figure 8.

The storage requirement for this case is dominated by the much larger LWR fleet. In this scenario, there is no plateau in spent fuel in storage because disposal of LWR fuel from Sizewell B overlaps with the end of generation of the larger new build fleet.

For fuel from new build reactors, long-term storage will be required from around 2035, rising to around 72,000 teU in 2130. This peak is, however, transient, as fuel begins to be shipped to the GDF within few years. Given that fuel would spend some time in rector ponds prior to export to longterm storage (typically 5-10 years), the peak interim storage inventory could be somewhat lower if a suitably long-lived reusable storage facility is used. However, because this overlap occurs at the margins towards the end of generation and start of disposals, this is unlikely to have a significant effect (i.e. more than a few hundred teU) on peak storage requirements.

Figure 9 shows the pattern of transport flask shipments. In this scenario, the transfer of new build LWR fuels rises steadily in response to the generation profile (Fig. 9) but extends for much longer than expected. In this case, the disposal period is extended, as can be seen by comparison with Figure 10. This extension occurs because the peak rate of spent fuel generation exceeds the maximum declared GDF reception rate (as noted earlier). With adequate throughput at the disposal sites, the export period would be 


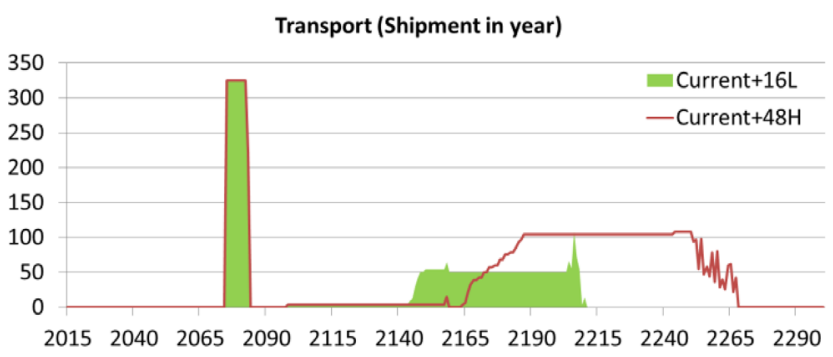

Fig. 9. Fuel transport requirements for high reference case.

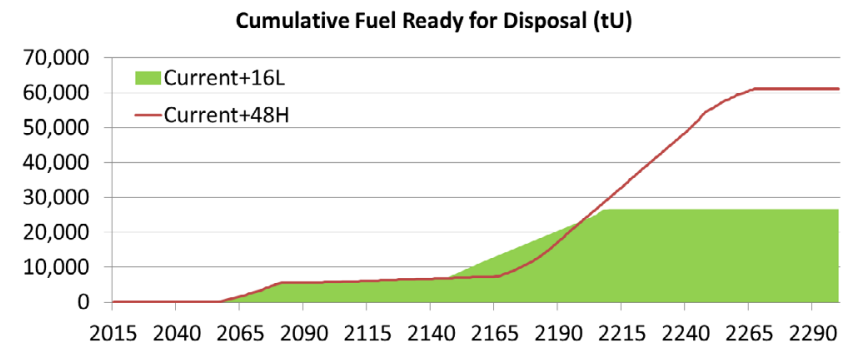

Fig. 10. Spent fuel availability for disposal for high reference case.

shortened to the point at which the cumulative curve in Figure 10 levels off. In this scenario, this would shorten the required storage period by around 20 years.

\section{Alternative disposal protocol}

RWM have proposed that storage times could be reduced by retaining spent fuel in interim storage until fuel discharged half way through the reactor life is ready for disposal [26]. Thereafter, progressively shorter- and longercooled fuels would be loaded into disposal containers until the final disposal container would contain the earliest discharged fuel and the last discharged fuel.

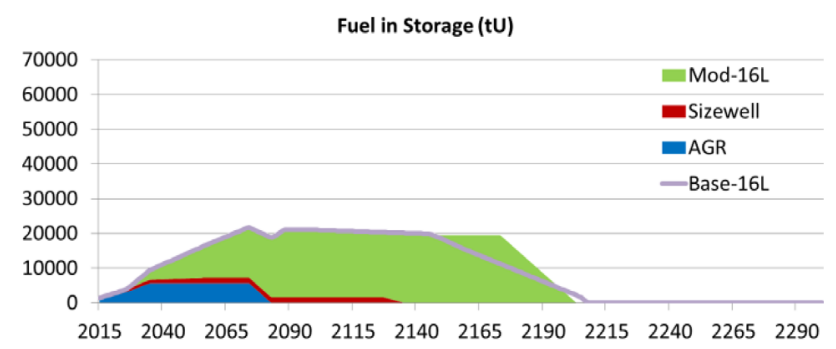

Fig. 11. Spent fuel storage requirements for low reference case and modified disposal protocol.

Table 4 provides a summary of the potential benefits of this approach using data for PWR fuel at two burn-ups and for two reactor operating lives, 60 years and 80 years. The adjusted minimum cooling period $\left(t_{2}\right)$ is the cooling time at which two assemblies at that cooling time plus two assemblies at that cooling time plus the operational life of the reactor $\left(t_{\mathrm{r}}\right)$ would have the same heat output as four assemblies with the reference cooling time $\left(t_{1}\right)$, which is approximately the time at which the fuel discharged half way through the plant's operating life would meet disposal requirements.

Using this approach, fuel disposals start at $t_{1}$ and end at $\left(\frac{1}{2} t_{\mathrm{r}}+t_{2}\right)$. The minimum time over which fuel can be disposed of is given by $\frac{1}{2} t_{\mathrm{r}}-\left(t_{1}-t_{2}\right)$. Table 4 indicates that reductions in fuel storage times of 25-30 years (or 18-27\%) are possible. However, it is also clear that the later start of fuel exports leads to significant increases in the rate at which fuel would need to be exported in order to achieve these benefits. It is likely, therefore, that a realistic strategy will be a compromise between minimising storage times and maintaining realistic processing rates.

\subsection{Storage profile for low reference case with modified disposal protocol}

The profile of fuel in storage for this case is shown in Figure 11.

Table 4. Adjusted cooling times for disposals.

\begin{tabular}{llrrrr}
\hline & & \multicolumn{3}{c}{ PWR } \\
\cline { 2 - 5 } Burn-up & GWd/teU & 55 & 65 & 55 & 65 \\
Operation & Years & 60 & 60 & 80 & 80 \\
Mid-life & Years & 30 & 30 & 40 & 40 \\
Minimum cooling time & Years & 120 & 140 & 120 & 140 \\
Start of fuel disposal & Years & 120 & 140 & 120 & 140 \\
End of fuel disposal & Years & 180 & 200 & 200 & 220 \\
Adjusted minimum cooling time & Years & 93 & 118 & 89 & 111 \\
Start of fuel disposal & Years & 150 & 170 & 160 & 180 \\
End of fuel disposal & Years & 153 & 178 & 169 & 191 \\
Transfer period & Years & 3 & 8 & 9 & 11 \\
Shipping rate multiplier & & 12 & 18 & 8 & 9 \\
Reduced storage time & Years & 27 & 22 & 31 & 29 \\
\hline
\end{tabular}




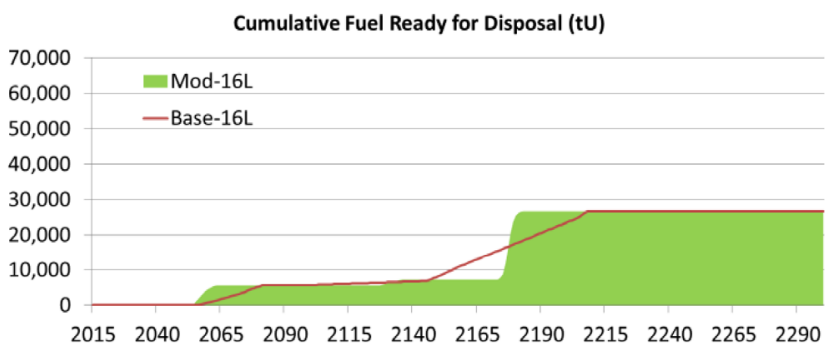

Fig. 12. Spent fuel availability for disposal for low reference case and modified disposal protocol.

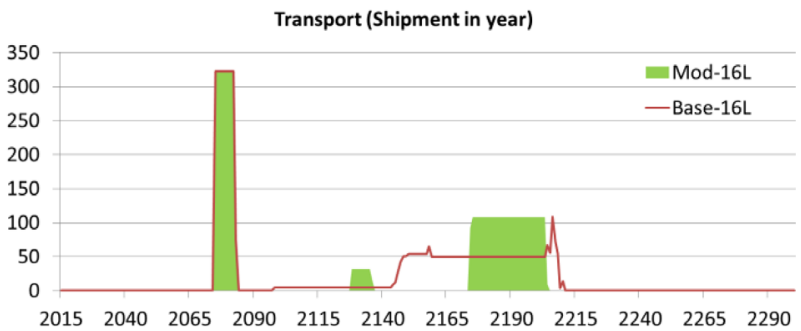

Fig. 13. Fuel transport requirements for low reference case and modified disposal protocol.

Comparison with Figure 5 shows a small reduction in maximum inventory of around 900 teU using the modified protocol, due to a more rapid export of fuel from current generation reactors, and a reduction in storage time of 7 years. This time saving is less than might be expected from Table 4 because the rate at which spent fuel becomes available for disposal is much greater than for the original scenario (compare Fig. 12 and Fig. 7). This is also evidence in the shorter periods over which fuel shipments occur and the higher annual movements (compare Fig. 13 and Fig. 6).

Unlike the original scenario where there was a short interval between AGR shipments and Sizewell B shipments and an overlap between Sizewell B and new build fuel shipments, in this case there are three distinct periods of shipments, isolated by periods of 45 and 28 years with no shipments. In each case, these intervals are significant fractions of a person's working life and where At-Reactor storage is selected, the challenges discussed above in relation to re-starting transport activities would be replicated prior to each series of shipments. Even for centralised storage, there would be two periods, of around 30 years, during which no fuel shipments would be scheduled.

\subsection{Storage profile for high reference case with modified disposal protocol}

The profile of fuel in storage for this case is shown in Figure 14. This clearly shows increases both in stored inventory and duration of storage. It was noted in the original scenario (Sect. 4.3) that fuel exports were being constrained by the design basis capacity of the GDF to received spent fuel. In this scenario, the rate at which fuel is to be transferred is much higher and hence the effects of constrained export rates are more pronounced.

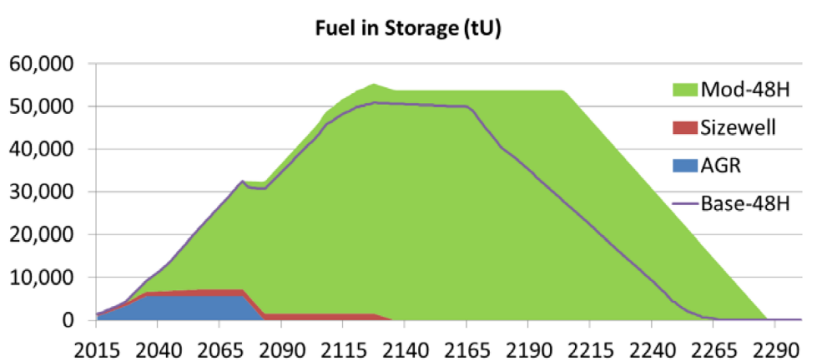

Fig. 14. Spent fuel storage requirements for high reference case and modified disposal protocol.

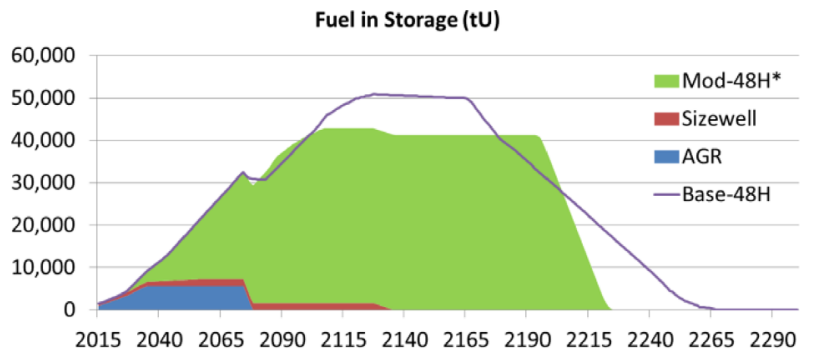

Fig. 15. Spent fuel storage requirements for high reference case, modified disposal protocol and increased DGF capacity.

To obtain a more realistic comparison, a scenario involving a higher receipt capacity of $1,500 \mathrm{teU} / \mathrm{y}$ has been run to identify potential benefits of the modified disposal strategy.

In this case, the maximum quantity of fuel in storage remains the same, but the period of storage is significantly reduced, by around 65 years (compare Fig. 14 and Fig. 15). Compared to the original disposal protocol, there is a modest increase in maximum fuel inventory (around 5,000 teU) and a reduction in storage time of around 30 years.

Even in this scenario the rate at which fuel can be received at a GDF is still extending the storage period beyond that at which fuel meets disposal criteria (compare Fig. 16 and Fig. 17) by around 15 years. Theoretical estimates of the reduction of storage time that can be gained from fuel mixing are unlikely to be achievable in many scenarios due to practical limitations. However, there is good evidence that a mixing strategy can produce significant reductions in storage times, provided that storage and/or packaging facilities are designed to allow effective mixing of fuels of different ages.

The intervals between phases of fuel shipments are increased again in this scenario with three district phases of transport separated by $\sim 30, \sim 40$ and $\sim 40$ years. Thus the modified disposal protocol will have an unintended consequence of increasing the start-up requirements for each period of fuel shipments because the intervals are approaching those of a working lifetime.

For many storage systems, the ability to mix fuel of different ages would require more infrastructure than would be required for simply exporting fuel as it reaches the minimum cooling requirements. It is also clear for scenarios such as this that multiple repacking lines would be required to achieve the necessary shipment rates or that repacking would have to be undertaken over a long period to prepare 


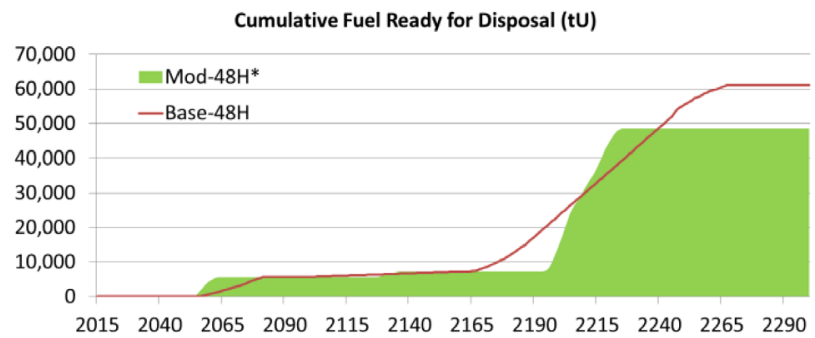

Fig. 16. Fuel transport requirements for high reference case, modified disposal protocol and increased GDF capacity.

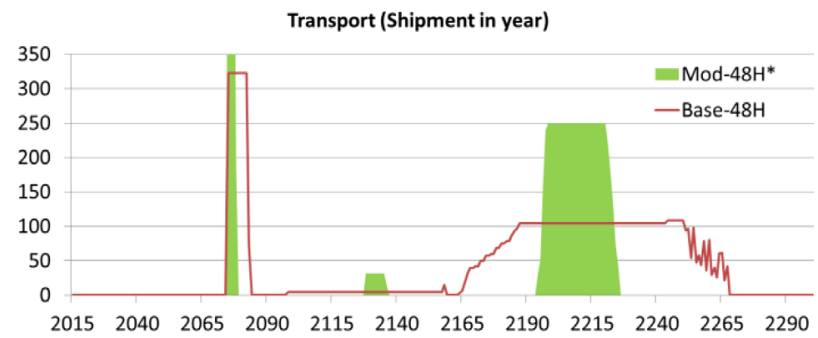

Fig. 17. Spent fuel availability for disposal high reference case, modified disposal protocol and increased DGF capacity.

fuel for shipping. This would, however, require additional storage facilities that may obviate any benefits from such a strategy.

For large consolidated storage facilities holding fuel from more than one reactor, the opportunities of further reductions in storage times may exist. However, it is highly likely that such benefits may be largely off-set by the constraints imposed by the maximum rate at which fuel can be exported.

Whilst it is clear that the maximum benefit that could be obtained from mixing of fuels of different ages is unlikely to be achievable, it suggests that in scenarios where a relatively small quantity of MOX fuel might be used in an LWR fleet, such strategies might also be effective in ameliorating to some extent the higher footprint of MOX fuel in a repository.

\section{Conclusions}

This assessment has identified potential scale and durations of spent fuel storage requirements faced by the UK for future nuclear power generation of $16 \mathrm{GWe}$ by 2030 and 48 GWe by 2050 .

The evaluation has identified the important influence of end point characteristics (e.g. disposal facility emplacement rates) on spent fuel storage and hence highlights the need for integrated planning for storage and either disposal or reprocessing.

The potentially long duration of spent fuel storage can lead to repeated occasions where transport operations have to be restarted after many decades of low or no activity. This represents a significant challenge for operators and regulators and may create points at which lack of familiarity could exacerbate public concern.
Mixing of fuels of different ages can lead to shorter storage times, in some cases by decades. The extent of the benefit will be constrained by the maximum rate at which fuel can be recovered from storage and processed through to emplacement. This option may lead to increased infrastructure requirements that may off-set some of the benefits.

Fuel mixing has been examined in the context of fuel from individual reactors. Wider mixing at centralised facilities has a potential for further benefits, particularly in relation to disposal of small quantities of MOX fuel.

This work was funded from the NNL's Strategic Research Programme on Spent Fuel Management and Disposal.

\section{References}

1. UK Department of Energy and Climate Change, Fourth National Report of Compliance with the Obligations of the Joint Convention on the Safety of Spent Fuel Management and on the Safety of Radioactive Waste Management, September 2011

2. Nuclear Decommissioning Authority, Fuel Strategy Position Paper, Magnox Fuel - Issue 1, July 2012

3. Nuclear Decommissioning Authority, Oxide Fuels - Preferred Option, SMS/TS/C2-OF/001/Preferred Option, June 2012

4. EDF, The Sizewell B Spent Fuel Management Option Study, 2010

5. UK HM Government, The Carbon Plan: Delivering our low carbon future, December 2011

6. Royal Commission on Environmental Pollution, "Nuclear Power and the Environment", Sixth Report of the Royal Commission on Environmental Pollution, Cm 6618, HMSO, 1976

7. Nuclear Decommissioning Authority, Geological Disposal Steps towards implementation - Executive Summary, ISBN 978184029402 6, March 2010

8. UK Department of Energy and Climate Change, Implementing Geological Disposal, July 2014

9. Z. Hodgson, D.I. Hambley, R. Gregg, D.N. Ross, The United Kingdom's Changing Requirements for Spent Fuel Storage, in Global 2013, Salt Lake City, USA (2013)

10. EDF, EDF Energy Nuclear Generation: Our journey towards zero harm, May 2014

11. EDF, website: https://www.edfenergy.com/energy, 18 March 2014

12. Lake Acquisitions Limited, Life extension of Dungeness B power station, RNS Number: 6225C, January 2015

13. D.I. Hambley, Technical Basis for Extending Storage of the UK's Advanced Gas-Cooled Reactor Fuel, in Global 2013, Salt Lake City, USA (2013)

14. E. Nonbøl, Description of the Advanced Gas Cooled Type of Reactor (AGR), Ris $\emptyset$ National Laboratory Report NKS/ RAK2(96)TR-C2, November 1996

15. Nuclear Decommissioning Authority, Packaging of Sizewell B Spent Fuel (Pre-Conceptual stage), Summary of Assessment Report, December 2011

16. E. Stokke, G. Meyer, Description of Sizewell B Nuclear Power Plant, Institutt for Energiteknikk (IFE) OECD Halden Reactor Project report NKS/RAK-2(97)TR-C4, September 1997

17. BBC News, UK nuclear power plant gets go-ahead, 21 October 2013 
18. Horizon Power, Wylfa Newydd Project Pre-Application Consultation - Stage One Consultation Overview Document, September 2014

19. NuGen, Stage 1, Strategic Issues Consultation, May 2015

20. D.P. Blair, UK EPR PCSR - Sub-chapter 4.3 - Nuclear Design, UKEPR-0002-043, Issue 05, July 2012

21. T. Le Coutois, Interim storage facility for spent fuel assemblies coming from an EPR plant, EDF ELI0800224 A, November 2008

22. GE-Hitachi, UK ABWR Generic Design Assessment -Preliminary Safety Report on Spent Fuel Interim Storage, XE-GD0155, Revision A, August 2014

23. GE-Hitachi, UK ABWR Generic Design Assessment -Generic PCSR Chapter 11: Reactor Core, UE-GD-0182 Rev A, August 2014
24. Westinghouse, AP1000 Pre-construction Safety Report, UKP-GW-GL-732 Rev 1, 2009

25. Nuclear Decommissioning Authority, Generic Design Assessment: Summary of Disposability Assessment for Wastes and Spent Fuel arising from Operation of the Westinghouse AP1000, NDA Technical Note No. 11261814, October 2009

26. Nuclear Decommissioning Authority, Geological Disposal, Feasibility Studies Exploring Options for Storage, Transport and Disposal of Spent Fuel from Potential New Nuclear Power Stations, NDA report NDA/RWMD/060/Rev 1, January 2014

27. Nuclear Decommissioning Authority, Packaging of Spent AGR Fuel (Preliminary stage), Summary of Assessment Report, April 2012

Cite this article as: David Hambley, Storage of thermal reactor fuels - Implications for the back end of the fuel cycle in the UK, EPJ

Nuclear Sci. Technol. 2, 21 (2016) 